\title{
Correlation between the Concentrations of Atmospheric Ions and Radon as Judged from Measurements at the Fonovaya Observatory
}

\author{
M. Yu. Arshinov ${ }^{a}$, B. D. Belan ${ }^{a, *}$, O. V. Garmash ${ }^{b}$, D. K. Davydov ${ }^{a}$, A. A. Demakova ${ }^{b}$, \\ E. V. Ezhova ${ }^{b}$, A. V. Kozlov ${ }^{a}$, M. Kulmala ${ }^{b}$, H. Lappalainen ${ }^{b}$, and T. Petäjä ${ }^{b}$ \\ ${ }^{a}$ V.E. Zuev Institute of Atmospheric Optics, Siberian Branch, Russian Academy of Sciences, Tomsk, 634055 Russia \\ ${ }^{b}$ Institute for Atmospheric and Earth System Research, University of Helsinki, Helsinki, FI-00014 Finland \\ *e-mail: bbd@iao.ru \\ Received November 29, 2021; revised November 29, 2021; accepted November 29, 2021
}

\begin{abstract}
The correlation between the radon influx into the atmosphere and the formation of ions has been studied from the data of observations at the Fonovaya Observatory of Institute of Atmospheric Optics, Siberian Branch, Russian Academy of Sciences. This correlation is shown to be stable in the period from October to January. In the other months, the correlation is disturbed. However, if the events of nucleation and lightning discharges are removed from the data set, then the correlation is kept throughout the year.
\end{abstract}

Keywords: atmosphere, air, ions, nanoparticles, neutral particles, nucleation, radon, interconnection

DOI: $10.1134 / \mathrm{S} 1024856022010158$

\section{INTRODUCTION}

According to the Sixth Assessment Report of the Intergovernmental Panel on Climate Change [1], atmospheric aerosol still introduces the greatest uncertainty in the radiation block when estimating the contribution of individual air pollutants to global climate warming. In the last century, it was found [2] that the aerosol process in the atmosphere starts with the formation (nucleation) of nanoparticles from molecules of trace atmospheric gases. Further, these particles attain the sizes of the radiation-significant accumulation fraction during condensation growth and coagulation [3-5].

The presence of charged particles (ions) in the atmosphere is an important factor of formation of new particles [6]. For example, the appearance of neutral particles of $2 \mathrm{~nm}$ in size is observed 20-30 min later than the appearance of 2-nm ions [7]. The study [8] has shown formation of ions in nighttime, which is not accompanied by the formation of neutral particles. The data [9] clarify that ions of 2-4 $\mathrm{nm}$ in size, being precursors of new particles, should have a number concentration of at least $20 \mathrm{~cm}^{-3}$. However, the available data on the role of ions in formation of aerosol particles are contradictory. Thus, it is found in [10] that charged particles increase nucleation by $1-2$ orders of magnitude. In [11, 12], to the contrary, no significant changes were obtained. It has been shown in [13] on the basis of numerical simulation and laboratory modeling that charged particles can provide nucleation even at the minimal observed concentrations of sulfuric acid vapor. Consequently, studies of the role of ions in aerosol processes should be continued.

The main sources of ion formation are cosmic gamma radiation and gamma radiation resulting from the radioactive decay of such elements as radon [14-16]. Cosmic-ray ionization occurs throughout the troposphere and dominates over the seas and oceans, while radon isotopes determine the mode of ions in the surface air layer over land [17]. It was additionally found in [18] that ions can be formed due to friction in strong winds, although this way cannot be considered as main. The radon influx into the atmosphere significantly depends on the geographical position of a site under study [19-21], as well as on the meteorological and geophysical parameters [22, 23], including precipitation [24]. Thus, it is quite interesting to study how these processes manifest themselves in a particular geographic region not covered by such studies.

In this paper, we consider the temporal dynamics of the ion number concentration versus the radon content in a background area of the Tomsk Region.

\section{MEASUREMENT SITE AND EQUIPMENT}

Measurements of ions and radon were carried out at the Fonovaya (background) Observatory located in Western Siberia $\left(56^{\circ} 25^{\prime} \mathrm{N}, 84^{\circ} 04^{\prime} \mathrm{E}\right)$, on the right bank of the Ob River. It is surrounded by a boreal forest; the nearest industrial center, Tomsk, is $60 \mathrm{~km}$ east.

To measure ions, we used the NAIS spectrometer of neutral clusters and ions. It provides measurements of 
(a)
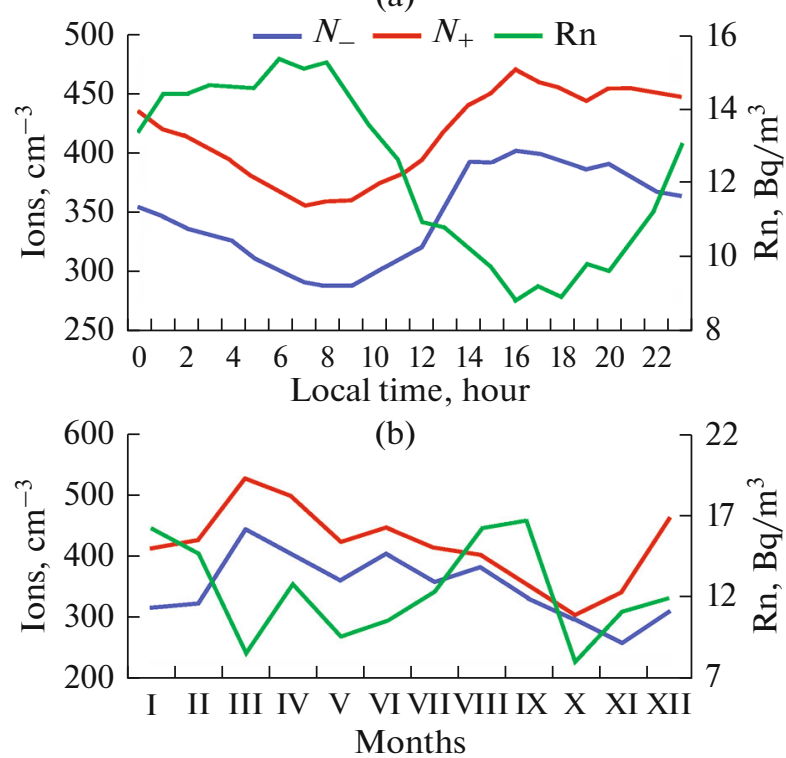

Fig. 1. (a) Daily and (b) annual variations in the number concentrations of air ion and radon.

the size distribution of clusters (aerosol particles) and air ions in the range $0.8-40 \mathrm{~nm}$ at the aerosol particle number concentration from 10 to $100000 \mathrm{~cm}^{-3}$ with an error of $10 \%$. The volumetric activity of radon $(\mathrm{Rn})$ and thoron (Tn) was measured with a SARAD RTM 2200 radiometer, operating in the range $0-107 \mathrm{~Bq} / \mathrm{m}^{3}$, with an error of $\pm 1 \mathrm{~Bq} / \mathrm{m}^{3}$. The observations of air ions began in July 2019, and of radon, in December 2019. The hourly measurements of meteorological parameters and gas and aerosol compositions simultaneously were carried out with the use of instruments of the observatory (see the detail description in [25].

\section{RESULTS AND DISCUSSION}

Since air ions and radon were not previously measured at the Fonovaya Observatory, consider first their temporal dynamics.

Figure 1 shows the daily variations in the total (of all sizes) number concentrations of negative $\left(N_{-}\right)$and positive $\left(N_{+}\right)$ions and radon, as well as the annual variations in the monthly average values.

As can be seen from Fig. 1a, the concentration of positive ions is slightly higher than that of negative ones throughout the day. The both curves show almost synchronous time behavior. As for the comparison between the diurnal variations in ions and radon, they are exactly opposite in phase. The radon concentration is maximal in nighttime and minimal in the afternoon. Since the underlying surface is a source of radon, this behavior is quite natural. A trapping layer forms at night, and the gas accumulates in the surface air layer. The trapping layer disappears in daytime, and radon begins to dissipate in the atmospheric boundary layer [26]. Ions which are formed immediately in the air behave differently. The number concentration of the ions is maximal in the afternoon and minimal in the morning. This behavior is characteristic of photochemical processes in the atmosphere, such as, for example, generation of ozone and other reactive particles [27].

The radon concentration measured in the Fonovaya Observatory is quite comparable with the values measured by other authors under similar conditions $[19,20,28]$. The results on the diurnal dynamics of radon also agree [29-32]. The number of observed ions, both positive and negative, lies within the ranges found by other authors [17, 33, 34]. The diurnal variations shown in Fig. 1a are similar to those given in [35-37]. Hence, our data correspond to the natural variability of the parameters under study.

As follows from Fig. 1b, the seasonal variations in the number concentrations of ions and radon are markedly different. The concentrations of both positive and negative ions are maximal in early spring and minimal in middle or late fall. In our opinion, this also reflects the role of photochemical processes in the formation of ions. The annual behavior of radon is different. We can seen two almost identical peaks, in winter (January) and in late summer-early fall, and two minima, in spring and in mid-fall.

An attempt to compare the annual variations in radon and air ions with data for other regions failed. The annual behaviors of these parameters differ in different regions [31, 32, 38-41]. Since our data are for 2020, this may be a consequence of the lockdown associated with the coronavirus pandemic. There are publications reporting the change in the air composition due to the decrease in emissions [42-45]. However, the processes associated with the lockdown could affect only the annual variation in ions, while the features of the annual variation in radon are apparently explained by other causes.

Let us analyze the correlation between the number concentrations of ions and radon. First, consider how it changes during the year according to hourly measurements (Table 1).

Though these parameters are opposite in phase, their variability is strong enough in different days to compensate for this feature. Thus, the correlation coefficients between the ions and radon are mostly positive (Table 1). There is a correlation between the ions and radon with different significance levels from October to January. Though both diurnal and annual average variations in the positive and negative ions are close (Fig. 1), the correlation between the ions and radon markedly depends on the ion sign. However, the correlation coefficients between ions of different sign and radon are close in some months. This possibly depends on the way of formation of ions of certain sign.

Since the hourly radon concentrations very strongly fluctuate during the day, the correlation was analyzed for the daily average values to smooth out the existing variability. These data are given in Table 2. 


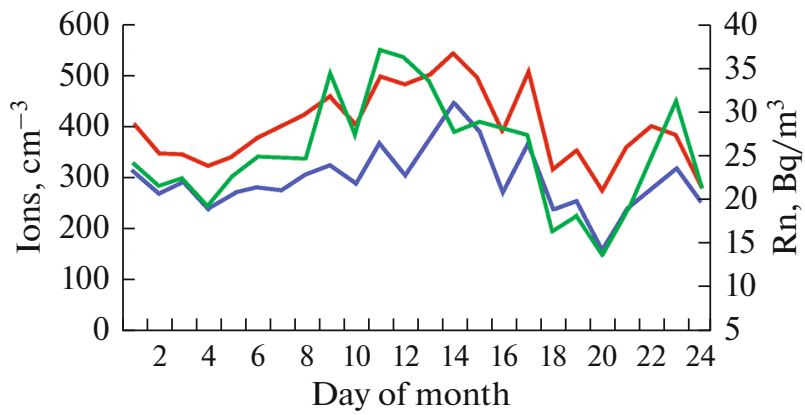

Fig. 2. Daily average concentrations of radon and positive $\left(N_{+}\right)$and negative $\left(N_{-}\right)$ions in January 2020 .

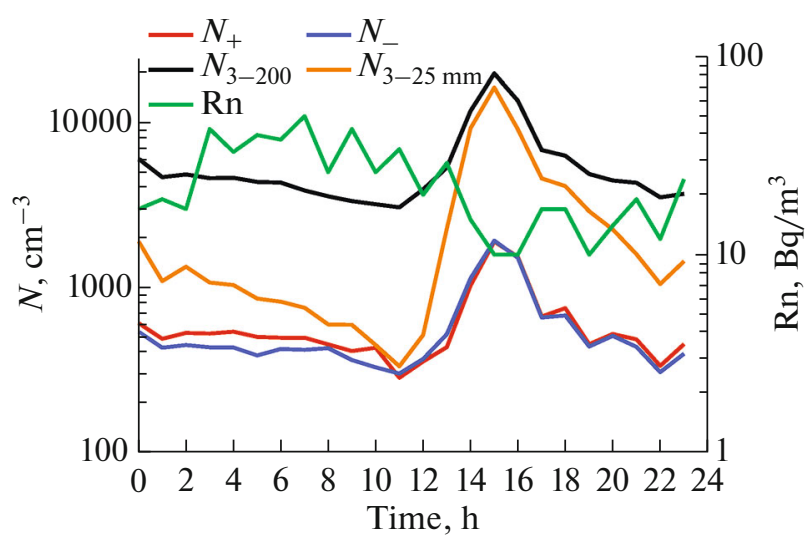

Fig. 3. Dynamics of the concentrations of radon, positive and negative ions, particles of the nucleation mode $\left(N_{3-25} \mathrm{~nm}\right)$, and total number concentration of nanoparticles $\left(N_{3-200 \mathrm{~nm}}\right)$ at the Fonovaya Observatory on September 21, 2020.

The comparison of Tables 1 and 2 shows that the smoothing procedure has not increased the correlation between ions and radon, although the period when the correlation is observed has somewhat extended. It begins in September. This is somewhat strange, since the comparison of the daily average values in Fig. 2 shows their quite synchronous variations.

The above analysis implies the existence of periods in the year with a stable, sometimes at the highest significance level, correlation between radon and formation of ions, as well as of periods where this correlation is not observed.

To understand possible causes of the difference in the behavior of ions and radon, we should remember that ions in the surface air layer originate during thunderstorms and, as noted above, during generation of nanoparticles. As is noted in numerous papers [47-50], ions of both signs can simultaneously originate in the case of the generation of new particles. The processes of generation of new nanoparticles are enhanced by ultraviolet radiation, which witnesses their photochemical mechanism [51, 52]. To explain this, let us consider Fig. 3 for example. It shows the generation of new particles on September 21, 2020, as well as the concentration of the nucleation mode $\left(N_{3-25 \mathrm{~nm}}\right)$ and the total number concentration of nanoparticles $\left(N_{3-200 \mathrm{~nm}}\right)$.

As seen in Fig. 3, new neutral aerosol particles originated in the period from 11:00 to 17:00 local time, which can be judged from the total concentration of particles and aerosols of the nucleation mode. That process was accompanied by the growth of the number concentrations of both positive and negative ions. Neither growth nor consumption of radon was observed in that time. Consequently, frequent events of generation of new particles break the correlation between variations in the ions and radon. The more frequent these events, the higher the differences.

The formation of ions during thunderstorms can be considered in Fig. 4 taken as an example. In contrast to the generation of new particles, the number of ions

Table 1. Correlation coefficients between the hourly concentrations of radon and negative $\left(N_{-}\right)$and positive $\left(N_{+}\right)$ions at the Fonovaya Observatory in 2020

\begin{tabular}{c|c|c|c|c|c|c|c|c|c|c|c|c}
\hline Month & 1 & 2 & 3 & 4 & 5 & 6 & 7 & 8 & 9 & 10 & 11 & 12 \\
\hline$N_{-}$ & $\mathbf{0 . 2 5}$ & -0.03 & $\mathbf{0 . 1 3}$ & $-\mathbf{0 . 1 0}$ & 0.01 & -0.07 & $\mathbf{0 . 0 8}^{* *}$ & $\mathbf{0 . 0 8}$ & 0.05 & $\mathbf{0 . 2 8} * * *$ & $\mathbf{0 . 4 3}^{* * *}$ & $\mathbf{0 . 1 6}^{* * *}$ \\
$N_{+}$ & $\mathbf{0 . 6 0}$ & $\mathbf{0 . 0 9}$ & $\mathbf{0 . 1 4}$ & -0.03 & 0.03 & -0.03 & 0.07 & -0.01 & $\mathbf{0 . 1 2}$ & $\mathbf{0 . 2 9} * * *$ & $\mathbf{0 . 5 1} * * *$ & $\mathbf{0 . 1 9}^{* * *}$ \\
Number of events & 727 & 528 & 367 & 714 & 743 & 670 & 744 & 744 & 720 & 560 & 720 & 401 \\
\hline
\end{tabular}

* The significance level with 0.05 probability;

** the significance level with 0.01 probability;

*** the significance level with 0.001 probability [46].

Table 2. Correlation coefficients between the daily average concentrations of radon and negative and positive ions at the Fonovaya Observatory in 2020 (designations are the same as in Table 1)

\begin{tabular}{|c|c|c|c|c|c|c|c|c|c|c|c|c|}
\hline Month & 1 & 2 & 3 & 4 & 5 & 6 & 7 & 8 & 9 & 10 & 11 & 12 \\
\hline$N_{-}$ & $0.58^{* *}$ & -0.07 & 0.35 & -0.08 & 0.14 & 0.03 & $0.35^{*}$ & -0.14 & $0.66^{* * *}$ & $0.59 * *$ & $0.54^{* *}$ & 0.43 \\
\hline$N_{+}$ & $0.71^{\text {**** }}$ & 0.06 & 0.36 & 0.09 & 0.24 & 0.08 & $0.44^{*}$ & -0.03 & $0.46^{* *}$ & $0.59^{* *}$ & $0.70^{* * *}$ & $0.48^{*}$ \\
\hline Number of events & 24 & 22 & 29 & 30 & 31 & 28 & 31 & 31 & 30 & 23 & 30 & 19 \\
\hline
\end{tabular}


generated during a thunderstorm is significantly larger than that of neutral particles. In Fig. 4, the concentration of ions increased by almost an order of magnitude at about 18:00 local time, when a thunderstorm passed over the observatory, while the content of neutral particles increased only several times. The radon concentration remained within the limits of natural daily variability.

Finally, Figure 5 shows variations in the concentrations of radon, ions, and neutral particles for the period where neither nucleation nor thunderstorm was observed. One can see that the variability of all the parameters remains within an order of magnitude. Radon, with allowance for the inter-hour fluctuations, follows the time behavior of the ions under quiet conditions. The $N_{3-25 \mathrm{~nm}}$ and $N_{3-200 \mathrm{~nm}}$ curves follows the ion variations.

We have excluded days with thunderstorms and banana-type nucleation events from the general data set used to compile Table 1 and calculated the correlation coefficients between ions and radon. The results are given in Table 3 . The correlation between positive ions and radon exists almost throughout the year, except for August. For negative ions, no correlation is observed in February, April, and June. As compared to Table 1, the correlation has appeared or its level of significance has increased. Thus, if we remove from the sample the events where ions are formed in the atmosphere in other way than charging particles with radon decay products, then the correlation between ions and radon exists throughout the year. The absence of the correlation in some months is most likely caused by the fact that nucleation events of other types, besides the banana type, were not removed from the sample.

To illustrate the correlation between the concentration of radon and the concentration of positively and negatively charged ions, the corresponding scatter diagrams were plotted based on the hourly measurements (Fig. 6). Figures 6a and 6b show all available data for 2020, and Figs. 6c and 6d, data where the concentration of neutral particles does not exceed $2000 \mathrm{~cm}^{-3}$. The chosen threshold corresponds to the typical concentration of neutral particles in the background atmosphere over the boreal forest.

As is seen in Figs. 6a and 6b, high concentrations of ions coincide with high concentrations of neutral particles (burst nucleation events). Most dark red dots are

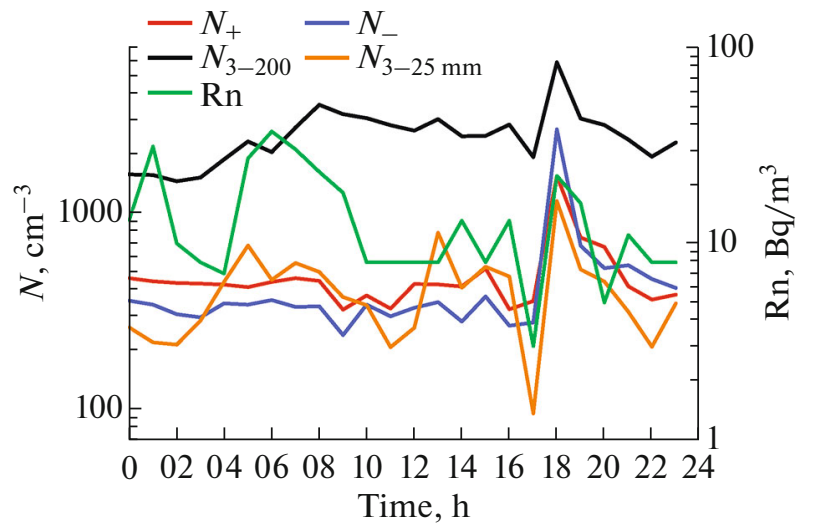

Fig. 4. The same as in Fig. 3, but on June 26, 2020.

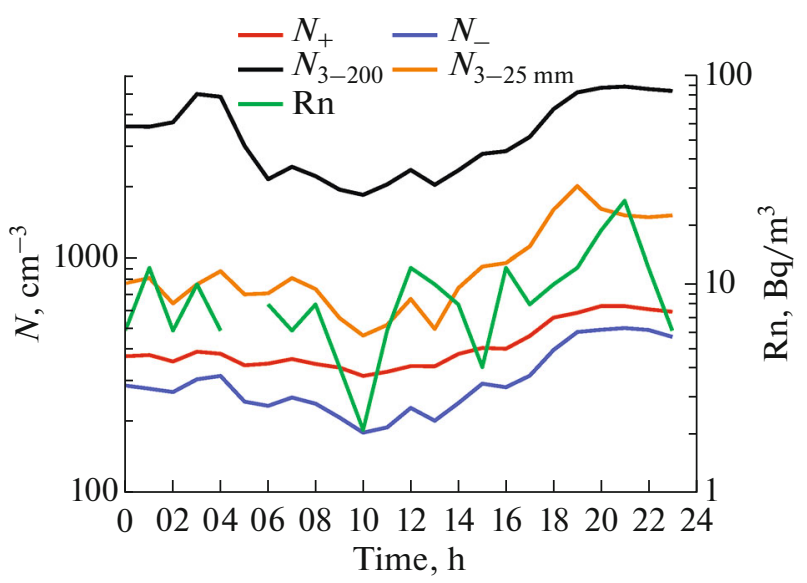

Fig. 5. The same as in Fig. 3, but on January 16, 2021.

located in the upper part of these figures and answer sufficiently low radon concentrations $\left(<20 \mathrm{~Bq} / \mathrm{m}^{-3}\right)$; hence, radon does not have a significant effect on the formation of ions during burst nucleation. In usual days, an increase in the lower limit of the concentrations of ions is observed with an increase in the radon concentration at low concentrations of neutral particles. For clarity, the scatter diagrams corresponding to low concentrations of neutral particles are separately shown in Figs. $6 \mathrm{c}$ and $6 \mathrm{~d}$. It can be seen that the concentration of ions increases from $60-80$ to $350-400 \mathrm{~cm}^{-3}$ as the radon concentration increases. Thus, in usual days, the radon concentration in the atmosphere determines the lower limit of the ion concentration.

Table 3. Correlation coefficients between hourly concentrations of radon and negative $\left(N_{-}\right)$and positive $\left(N_{+}\right)$ions at the Fonovaya observatory in 2020 , without nucleation and thunderstorm events

\begin{tabular}{|c|c|c|c|c|c|c|c|c|c|c|c|c|}
\hline Month & 1 & 2 & 3 & 4 & 5 & 6 & 7 & 8 & 9 & 10 & 11 & 12 \\
\hline$N_{-}$ & $0.36^{* * *}$ & -0.03 & $0.16^{* *}$ & -0.01 & $0.08 *$ & 0.05 & 0.09* & $0.13^{* *}$ & $0.14 * *$ & $0.28 * * *$ & $0.43^{* * *}$ & $0.16^{* * *}$ \\
\hline$N_{+}$ & $0.50 * * *$ & $0.11 *$ & $0.20^{* *}$ & $0.14^{* *}$ & $0.16^{* *}$ & $0.10 *$ & $0.11^{* *}$ & 0.05 & $0.27^{* *}$ & $0.29 * * *$ & $0.51 * * *$ & $0.19 * * *$ \\
\hline $\begin{array}{l}\text { Number } \\
\text { of events }\end{array}$ & 543 & 510 & 278 & 638 & 687 & 623 & 728 & 674 & 681 & 560 & 720 & 401 \\
\hline
\end{tabular}



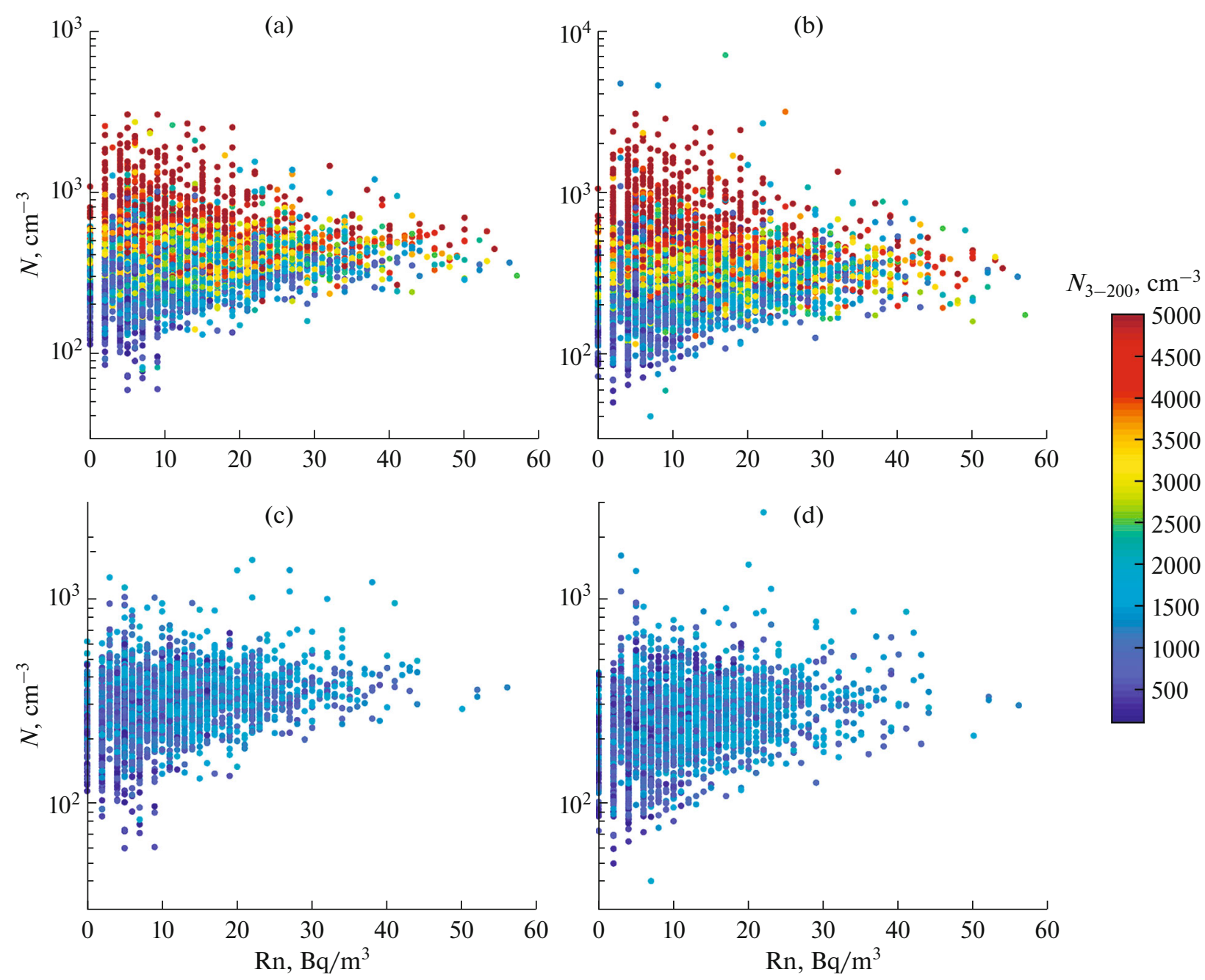

Fig. 6. Scatter diagram: (a) radon-positively charged air ions, all data; (b) radon-negatively charged air ions, all data; (c) radon-positively charged air ions, neutral particle $\left(3 \mathrm{~nm}<D_{p}<200 \mathrm{~nm}\right)$ concentration is below $2000 \mathrm{~cm}^{-3}$; (d) radonnegatively charged air ions, neutral particle concentration is below $2000 \mathrm{~cm}^{-3}$.

\section{CONCLUSIONS}

The study has shown that formation of ions due to charging with the radon decay products is observed throughout the year. This process can be masked by more active processes of ion formation in the atmosphere, for example, those accompanying burst nucleation or lightning discharges. When these events are removed from the sample, the concentrations of radon and ions correlate. Thus, statistically significant, although often weak, the correlations between the concentrations of radon and ions indicate a certain role of radon in ion formation throughout the year, except for nucleation and thunderstorm events.

\section{FUNDING}

The study was supported by the Ministry of Science and Higher Education of the Russian Federation within the "Development of the Measuring System of the Fonovaya Observatory for Research under the PEEX (Pan-Eurasian
EXperiment) International Program" Project (agreement no. 075-15-2021-977).

\section{CONFLICT OF INTEREST}

The authors declare that they have no conflicts of interest.

\section{REFERENCES}

1. "Summary for policymakers," in: Climate Change 2021: The Physical Science Basis. Contribution of Working Group I to the Sixth Assessment Report of the Intergovernmental Panel on Climate Change (Cambridge University Press, 2021), p. 1-41.

2. N. A. Fuks, The Mechanics of Aerosols (Macmillan, 1964).

3. G. V. Rosenberg, Yu. S. Lyubovtseva, and G. I. Gorchakov, "Background aerosol of Abastumani," Izv. Akad. Nauk SSSR, Fiz. Atmos. Okeana 18 (8), 822839 (1982). 
4. G. V. Rosenberg, "Appearance and development of atmospheric aerosol-kinetically justified parameters," Izv. Akad. Nauk SSSR, Fiz. Atmos. Okeana 19 (1), 2135 (1983).

5. G. V. Rosenberg, "Kinetic model of dehydrated finely dispersed tropospheric aerosol," Izv. Akad. Nauk SSSR, Fiz. Atmos. Okeana 19 (3), 241-254 (1983).

6. A. Hirsikko, T. Nieminen, S. Gagne, K. Lehtipalo, H. E. Manninen, M. Ehn, U. Horrak, V.-M. Kerminen, L. Laakso, P. H. McMurry, A. Mirme, S. Mirme, T. Petaja, H. Tammet, V. Vakkari, M. Vana, and M. Kulmala, "Atmospheric ions and nucleation: A review of observations," Atmos. Chem. Phys. 11 (2), 767-798 (2011).

7. M. Kulmala, H. E. Manninen, A. Wiedensohler, and A. Held, "Ion-particle interactions during particle formation and growth at a coniferous forest site in Central Europe," Atmos. Chem. Phys. 14 (19), 10547-10563 (2014).

8. S. B. Mazon, J. Kontkanen, H. E. Manninen, T. Nieminen, V.-M. Kerminen, and M. Kulmala, "A longterm comparison of nighttime cluster events and daytime ion formation in a boreal forest," Boreal Environ. Res. 21 (3-4), 242-261 (2016).

9. K. Leino, T. Nieminen, H. E. Manninen, T. Petäjä, V.-M. Kerminen, and M. Kulmala, "Intermediate ions as a strong indicator of new particle formation bursts in boreal forest," Boreal Environ. Res. 21 (3-4), 274-286 (2016).

10. F. Yu and R. P. Turco, "The size-dependent charge fraction of sub-3-nm particles as a key diagnostic of competitive nucleation mechanisms under atmospheric conditions," Atmos. Chem. Phys. 11 (18), 9451-9463 (2011)

11. J. Merikanto, J. Duplissy, A. Määttänen, H. Henschel, N. M. Donahue, D. Brus, S. Schobesberger, M. Kulmala, and H. Vehkamäki, "Effect of ions on sulfuric acid-water binary particle formation: 1 . Theory for kinetic- and nucleation-type particle formation and atmospheric implications," J. Geophys. Res. Atmos. 121 (4), 1736-1751 (2016).

12. E. M. Dunne, L. A. Lee, C. L. Reddington, and K. S. Carslaw, "No statistically significant effect of a short-term decrease in the nucleation rate on atmospheric aerosols," Atmos. Chem. Phys. 12 (23), 1157311587 (2012).

13. J. Kirkby, J. Duplissy, K. Sengupta, C. Frege, H. Gordon, C. Williamson, M. Heinritzi, M. Simon, C. Yan, J. Almeida, J. Tröst, T. Nieminen, I. K. Ortega, R. Wagner, A. Adamov, A. Amorim, A.-K. Bernhammer, F. Bianchi, M. Breitenlechner, S. Brilke, X. Chen, J. Craven, A. Dias, S. Ehrhart, R. C. Flagan, A. Franchin, C. Fuchs, R. Guida, J. Hakala, C. R. Hoyle, T. Jokinen, H. Junninen, J. Kangasluoma, J. Kim, M. Krapf, A. Kurten, A. Laaksonen, K. Lehtipalo, V. Makhmutov, S. Mathot, U. Molteni, A. Onnela, O. Perakyla, F. Piel, T. Petäjä, A. P. Praplan, K. Pringle, A. Rap, N. A. D. Richards, I. Riipinen, M. P. Rissanen, L. Rondo, N. Sarnela, S. Schobesberger, C. E. Scott, J. H. Seinfeld, M. Sipilä, G. Steiner, Y. Stozhkov, F. Stratmann, A. Tomé, A. Virtanen, A. L. Vogel, A. C. Wagner, P. E. Wagner, E. Weingartner, D. Wimmer, P. M. Winkler, P. Ye, X. Zhang, A. Hansel, J. Dommen, N. M. Donahue, D. R. Worsnop, U. Baltensperger, M. Kulmala, K. S. Carslaw, and J. Curtius,
"Ion-induced nucleation of pure biogenic particles," Nature 533 (7604), 521-526 (2016).

14. C. Serrano, A. H. Reis, R. Rosa, and P. A. Lucio, "Influences of cosmic radiation, artificial radioactivity and aerosol concentration upon the fair-weather atmospheric electric field in Lisbon (1955-1991)," Atmos. Res. 81 (2), 236-249 (2006).

15. S. N. Manohar, H. A. J. Meijer, and M. A. Herber, "Radon flux maps for the Netherlands and Europe using terrestrial gamma radiation derived from soil radionuclides," Atmos. Environ. 81, 399-412 (2013).

16. S. V. Anisimov, S. V. Galichenko, K. V. Afinogenov, A. P. Makrushin, and N. M. Shikhova, "Radon volumetric activity and ion production in the undisturbed lower atmosphere: Ground-based observations and numerical modeling," Izv., Phys. Solid Earth 53 (1), 147161 (2017).

17. M. Komppula, M. Vana, V.-M. Kerminen, H. Lihavainen, Y. Viisanen, U. Hõrrak, K. Komsaare, E. Tamm, A. Hirsikko, L. Laakso, and M. Kulmala, "Size distributions of atmospheric ions in the Baltic Sea region," Boreal Environ. Res. 12 (3), 323-336 (2007).

18. X. Chen, A. Virkkula, V.-M. Kerminen, H. E. Manninen, M. Busetto, C. Lanconelli, A. Lupi, V. Vitale, M. Del Guasta, P. Grigioni, R. Väänänen, E.-M. Duplissy, T. Petäjä, and M. Kulmala, "Features in air ions measured by an air ion spectrometer (AIS) at Dome C," Atmos. Chem. Phys. 17 (22), 13783-13800 (2017).

19. K. Zhang, J. Feichter, J. Kazil, H. Wan, W. Zhuo, A. D. Griffiths, H. Sartorius, W. Zahorowski, M. Ramonet, M. Schmidt, C. Yver, R. E. M. Neubert, E.-G. Brunke, "Radon activity in the lower troposphere and its impact on ionization rate: A global estimate using different radon emissions," Atmos. Chem. Phys. 11 (15), 7817-7838 (2011).

20. I. López-Coto, J. L. Mas, and J. P. Bolivar, "A 40-year retrospective European radon flux inventory including climatological variability," Atmos. Environ. 73, 22-33 (2013).

21. E. V. Berezina, N. F. Elansky, K. B. Moiseenko, I. B. Belikov, R. A. Shumsky, A. N. Safronov, and C. A. M. Brenninkmeijer, "Estimation of nocturnal 222 Rn soil fluxes over Russia from TROICA measurements," Atmos. Chem. Phys. 23 (15), 11695-11708 (2013).

22. S. K. Sahoo, M. Katlamudi, J. P. Shaji, K. S. M. Krishna, and G. U. Lakshmi, "Influence of meteorological parameters on the soil radon ( $\mathrm{Rn} 222)$ emanation in Kutch, Gujarat, India," Environ. Monit. Assess. 190 (3), 111 (2018).

23. A. Podstawczynska, "Differences of near-ground atmospheric Rn-222 concentration between urban and rural area with reference to microclimate diversity," Atmos. Environ. 126, 225-234 (2016).

24. C. Bottardi, M. Alberi, M. Baldoncini, E. Chiarelli, M. Montuschi, K. G. C. Raptis, A. Serafini, V. Strati, and F. Mantovani, "Rain rate and radon daughters' activity," Atmos. Environ. 238, 117728 (2020).

25. V. V. Antonovich, P. N. Antokhin, M. Yu. Arshinov, B. D. Belan, Y. S. Balin, D. K. Davydov, G. A. Ivlev, A. V. Kozlov, V. S. Kozlov, G. P. Kokhanenko, and M. M. Novoselov, "Station for the comprehensive monitoring of the atmosphere at Fonovaya Observatory, West Siberia: Current status and future needs," Proc. SPIE 10833, 108337Z (2018). 
26. B. D. Belan, "Dynamics of the atmospheric mixing layer as it follows from data on aerosol," Atmos. Ocean. Opt. 7 (8), 558-562 (1994).

27. B. D. Belan, Tropospheric Ozone (Publishing House of IAO SB RAS, Tomsk, 2010) [in Russian].

28. J. Porstendorfer, "Properties and behavior of radon and thoron and their daughter products in air," in Problems of Environment and Natural Resources (VINITI, Moscow, 2001), is. 9, p. 59-98 [in Russian].

29. S. D. Chambers, A. G. Williams, J. Crawford, and A. D. Griffiths, "On the use of radon for quantifying the effects of atmospheric stability on urban emissions," Atmos. Chem. Phys. 15 (3), 1175-1190 (2015).

30. X. Chen, J. Paatero, V.-M. Kerminen, L. Riuttanen, J. Hatakka, V. Hiltunen, P. Paasonen, A. Hirsikko, A. Franchin, H. E. Manninen, T. Petäjä, Y. Viisanen, and M. Kulmala, "Responses of the atmospheric concentration of Radon-222 to the vertical mixing and spatial transportation," Boreal Environ. Res. 21 (3-4), 299-318 (2016).

31. N. J. Victor, D. Siingh, R. P. Singh, R. Singh, and A. K. Kamra, "Diurnal and seasonal variations of radon $(222 \mathrm{Rn})$ and their dependence on soil moisture and vertical stability of the lower atmosphere at Pune, India,” J. Atmos. Sol.-Terr. Phys. 195, 105118 (2019).

32. S. Chambers, A. G. Williams, W. Zahorowski, A. Griffiths, and J. Crawford, "Separating remote fetch and local mixing influences on vertical radon measurements in the lower atmosphere," Tellus B 63 (5), 843859 (2011).

33. Y. Wang, Ya. Wang, J. Duan, T. Cheng, H. Zhu, X. Xie, Y. Liu, Y. Ling, X. Li, H. Wang, M. Li, and R. Zhang, "Temporal variation of atmospheric static electric field and air ions and their relationships to pollution in Shanghai," Aerosol Air Qual. Res. 18 (7), 1631-1641 (2018).

34. Y. Li, X. Guo, T. Wang, Y. Zhao, H. Zhang, and W. Wang, "Characteristics of atmospheric small ions and their application to assessment of air quality in a typical semi-arid city of northwest China," Aerosol Air Qual. Res. 15 (3), 865-874 (2015).

35. N. Kamsali, S. D. Pawar, P. Murugavel, and V. Gopalakrishnan, "Estimation of small ion concentration near the Earth's surface,” J. Atmos. Sol.-Terr. Phys. 73 (16), 2345-2351 (2011).

36. X. Ling, R. Jayaratne, and L. Morawska, "The relationship between airborne small ions and particles in urban environments," Atmos. Environ. 79, 1-6 (2013).

37. V. N. Santos Dos, E. Herrmann, H. E. Manninen, T. Hussein, J. Hakala, T. Nieminen, P. P. Aalto, M. Merkel, A. Wiedensohler, M. Kulmala, T. Petäjä, and K. Hameri, "Variability of air ion concentrations in urban Paris," Atmos. Chem. Phys. 15 (23), 1371713737 (2015).

38. S. D. Chambers, S.-B. Hong, A. G. Williams, J. Crawford, A. D. Griffiths, and S.-J. Park, "Characterising terrestrial influences on Antarctic air masses using Radon-222 measurements at King George Island," Atmos. Chem. Phys. 14 (18), 9903-9916 (2014).

39. R. Bothaa, C. Labuschagne, A. G. Williams, G. Bosmane, E.-G. Brunke, A. Rossouw, and R. Lindsaya, "Characterising fifteen years of continuous atmospheric radon activity observations at Cape Point (South Africa)," Atmos. Environ. 176, 30-39 (2018).
40. N. Kalivitis, I. Stavroulas, A. Bougiatioti, G. Kouvarakis, S. Gagne, H. E. Manninen, M. Kulmala, and N. Mihalopoulos, "Night-time enhanced atmospheric ion concentrations in the marine boundary layer," Atmos. Chem. Phys. 12 (8), 3627-3638 (2012).

41. S. Miao, X. Zhang, Y. Han, W. Sun, C. Liu, and S. Yin, "Random forest algorithm for the relationship between negative air ions and environmental factors in an urban park," Atmosphere 9 (12), 463 (2018).

42. I. Salma, M. Vörösmarty, A. Z. Gyöngyösi, W. Thén, and T. Weidinger, "What can we learn about urban air quality with regard to the first outbreak of the COVID-19 Pandemic? A case study from Central Europe," Atmos. Chem. Phys. 20 (24), 15725-15742 (2020).

43. T. F. Johnson, L. A. Hordley, M. P. Greenwell, and L. C. Evans, "Associations between COVID-19 transmission rates, park use, and landscape structure," Sci. Total Environ. 789, 148123 (2021).

44. M. Mertens, P. Jöckel, S. Matthes, M. Nützel, V. Grewe, and R. Sausen, "COVID-19 induced lowertropospheric ozone changes," Environ. Res. Lett. 16 (6), 064005 (2021).

45. I. Bouarar, B. Gaubert, G. P. Brasseur, W. Steinbrecht, T. Doumbia, S. Tilmes, Y. Liu, T. Stavrakou, A. Deroubaix, S. Darras, C. Granier, F. Lacey, J.-F. Muller, X. Shi, N. Elguindi, and T. Wang, "Ozone anomalies in the free troposphere during the COVID-19 pandemic," Geophys. Res. Lett. 48 (16), 094204 (2021).

46. L. N. Bolshev, Mathematical Statistics Tables (Nauka, Moscow, 1983) [in Russian].

47. H. Tammet, K. Komsaare, and U. Horrak, "Intermediate ions in the atmosphere," Atmos. Res. 135-136, 263-273 (2014).

48. E. R. Jayaratne, X. Ling, and L. Morawska, "Suppression of cluster ions during rapidly increasing particle number concentration events in the environment," Aerosol Air Qual. Res. 15 (1), 28-37 (2015).

49. I. Salma, W. Thén, P. Aalto, V.-M. Kerminen, A. Kern, Z. Barcza, T. Petäjä, and M. Kulmala, "Influence of vegetation on occurrence and time distributions of regional new aerosol particle formation and growth," Atmos. Chem. Phys. 21 (4), 2861-2880 (2021).

50. H. Li, M. R. Canagaratna, M. Riva, P. Rantala, Y. Zhang, S. Thomas, L. Heikkinen, P.-M. Flaud, E. Villenave, E. Perraudin, D. Worsnop, M. Kulmala, M. Ehn, and F. Bianchi, "Atmospheric organic vapors in two European pine forests measured by a Vocus PTR-TOF: Insights into monoterpene and sesquiterpene oxidation processes," Atmos. Chem. Phys. 21 (5), 4123-4147 (2021).

51. C. Rose, K. Sellegri, E. Freney, R. Dupuy, A. Colomb, J.-M. Pichon, M. Ribeiro, T. Bourianne, F. Burnet, and A. Schwarzenboeck, "Airborne measurements of new particle formation in the free troposphere above the Mediterranean Sea during the HYMEX campaign," Atmos. Chem. Phys. 15 (17), 10203-10218 (2015).

52. B. Wehner, F. Werner, F. Ditas, R. A. Shaw, M. Kulmala, and H. Siebert, "Observations of new particle formation in enhanced UV irradiance zones near cumulus clouds," Atmos. Chem. Phys. 15 (17), 1020310218 (2015). 